\title{
Research and Development on Automatic Garlic Planting Machine
}

\author{
Xiaofei Dong \\ School of Mechanical Engineering \\ Yancheng Institute of Technology \\ Yancheng, China \\ E-mail: 328028944@qq.com
}

Jinlong Lu

School of Mechanical Engineering

Yancheng Institute of Technology

Yancheng, China

E-mail: 379784611@qq.com

\author{
Yun $\mathrm{Wu}$ * \\ School of Computer Science and Technology \\ Guizhou University \\ Guiyang, China \\ E-mail: wuyun_v@126.com \\ * Corresponding Author
}

\begin{abstract}
Garlic is a popular crop planted widely around the world, but garlic planting is a heavy work. This paper proposed an automatic machine which can achieve the automation of garlic planting. Based on the study of the main structure of the machine, the connection and transmission relationship of the machine were studied. The function of each main component was introduced in this paper, and the calculation method and steps of the power used to drive the machine were also given. The garlic automatic planting machine has a suitable design, which works in high efficiency, stability and economy.
\end{abstract}

Keywords-Garlic Planting Machine; Automatic Planting; Mechanization; Transmission System; Connection Relationship

\section{INTRODUCTION}

In recent years, due to the growing market demand, garlic production and sales are rising straightly. Garlic is getting more and more attention at home and abroad, and its planting area is increasing every year. Garlic is popular among the world for its taste and medical function. Garlic has an irregular shape, so the planting garlic usually requires the position of the garlic tip upward, which causes the result that garlic planting is usually finished by hand. The artificial planting has high labor intensity but in low production efficiency, resulting in high production cost. It has been planted in hundreds of the countries in the world. Garlic has been proved to own notable edible and medical value. Garlic has been a subject of considerable interest as a medicine world-wide since ancient times. Several lines of evidence through both in vitro and in vivo studies have revealed pharmacological potentials of garlic. In vitro studies demonstrated its antimicrobial [1], antithrombotic, anticancer, anti-platelet aggregation and antioxidant [2] activities [3]. Bulb size and regularity of shape and absence of defects determine garlic commercial quality, with these factors being related to variety, environment and cultural practices [4].
With the expansion of garlic cultivation and aggravation of human resources shortage, it is urgent to develop a garlic automatic planting machine, which can efficiently reduce labor intensity. In this paper, a garlic planting machine is designed, which can plant garlic seeds automatically. The garlic planting machine is designed to plant garlic, which is driven by small and medium-size tractors. The machine can plant garlic in wide-range in one time by metering garlic clove and adjusting the position of the garlic tips. The machine can achieve the goal of planting garlic in scale and mechanization.

The single-seeding of the garlic cover and maintain the garlic tip position upward when putting the garlic in hole are the key points of the improvements, this is the hard part and the key part. The feature of the machines abroad are seeding after trenching, and planting the garlic mechanization, and another is the realization of singleseeding of its' cover, but they did not solve the issue of the garlic tip position. The studies at home are solving these issues too [5-8]. A representative is five rows selfpropelled garlic planting machine, the feature of the machine is that it adopted the way of pouching first and seeding after. It no longer needed to add the garlic cover into the machine by hands. It obtained some certain results, but there are still few issues remained to solve. The machine needs to be improved.

At abroad, the mechanization production of the garlic has been standardized, such as the U.S.A, France. Australia researchers and engineers studied the garlic seed refrigerating treatment instrument. Many countries studied the appropriate seed-time, sowing quantity, planting density, fertilization type, and sprinkling irrigation [9-10].

The "green garlic" is becoming the focus of market demand. The mechanical technologies are mainly gathered in Japan, Korea and China. The other countries have some of the technologies too. Korea has 16 of the garlic planting machine's patents while Japan has 8 patents and China has only 8 patents too. The other countries have far less patents. 
These patents have only solved some basic problems in local planting.

So far, there are three ways of garlic planting mechanical technologies divided by planting patterns. The first one is garlic sow drop seeding technique, the efficiency of this kind of machines are sowing seeds with the speed of per one person per day. The second one is artificial supplementary seeding technique, and the efficiency of this machine is almost the same as the artificial cultivation, which is per one person per day. However, it can produce high quality of garlic. The third one is the full-automation seeding technique; it did not solve the problem of the position of garlic tip, because its design structure is too big. This machine will change backwardness in the research and development of farm machinery, and improve the mechanization and automation of agriculture.

Nowadays, for the growing of market demand, garlic production and sales are rising too. However, there are still many problems with the garlic planting machine, designing a machine which can fit in the environment and it is vital to the improvement of the current situation of the garlic planting machine internal. The design can fill in the gaps in the farm machinery design of China and achieve the goal of planting the garlic in scale and mechanization.

\section{OVERALL SCHEME DESIGN}

\section{A. Main Structure}

The garlic planting machine (as shown in the figure) can plant the garlic in wide-range for one-time by successfully adjusting the position of the garlic tips, which greatly reduced manual labor and improved the efficiency of planting the garlic. It can achieve the goal of planting the garlic in scale and mechanization. This machine has the trenching device 1 , planting device 2 , earthling device 3 , cams mechanism 4 , connector 5 , frame 6 , seed-metering device $7, \mathrm{~V}$-belt $8, \operatorname{cog}$ belt 9 , press wheel 10 and wheel 11 .

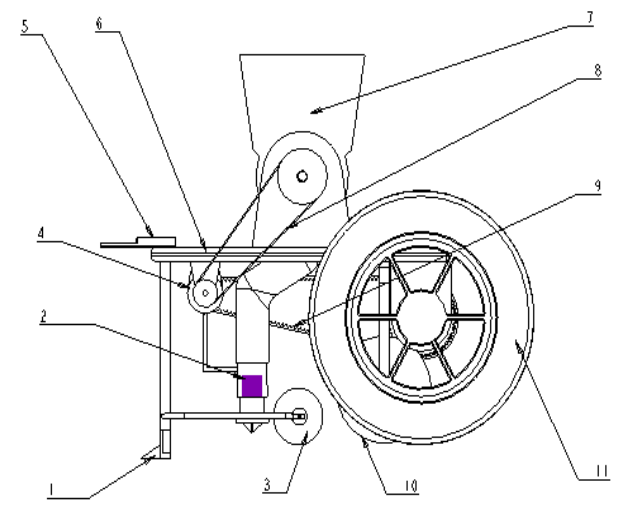

Figure 1.The garlic planting machine overall design

\section{B. Interconnection of the Major Parts}

The machine is connected by connector 5 and the body of the hauling engine. When the hauling engine is moving, it drives the garlic planting machine by connector 5 .

The machine is braced by the wheel 11 , and the machine gets running through its rotation. There is a trenching device 1 equipped in front, the trenching device 1 and the frame 6 are connected by bolts. The trenching device 1 has some inclination angle and is half buried in the mud. When the machine is running, the trenching device moves on the mud and makes the gully on the mud through its way. The planting device 2 and the seedmetering device 7 are fixed together and there is a pipe connected inside, the garlic will be dropped into the planting device 2 through the pipe inside by its own weight. The seed-metering device 7 is fixed on the frame 6.The earthing device 3 and the frame 6 is connected by bolts. The shell of the cams mechanism 4 is fixed on the frame. The press wheel 10 is installed on the frame 6 by bear and it can rotates around the frame 6.The wheel is installed on the frame 6 by bear, it can also rotates.

\section{Operation Principle of the Planting Device}

The planting device (as shown in the figure) is consisted of oscillating follower 2-1, reset spring 22 ,sleeve $2-3$, stopper $2-4$, retainer $2-5$, tightening ring $2-$ 6 ,sleeve $2-7$, slider $2-8$ and planting pipe 2-9. The oscillating follower 2-1 and planting pipe 2-9 are connected by bolts, when the cams mechanism 4 is rotating; it pushes the oscillating follower 2-1 to do reciprocating motion. While the oscillating follower 2-1 moving down, it pushes the planting pipe 2-9 to move down. Slider 2-8 is fixed on the planting pipe 2-9. The top of reset spring 2-2 is connected with planting pipe's trapezoidal surface and the bottom of it is connected with confining. The initial state of retainer $2-5$ is splayed, but the tightening ring stops it to splayed more. For the planting pipe keeps lowering, the reset spring starts to shrink gradually. The max radius of the tightening ring 2-6 is bigger than the max radius of retainer 2-5 and stopper 24 , so the stopper stops it from lowering.

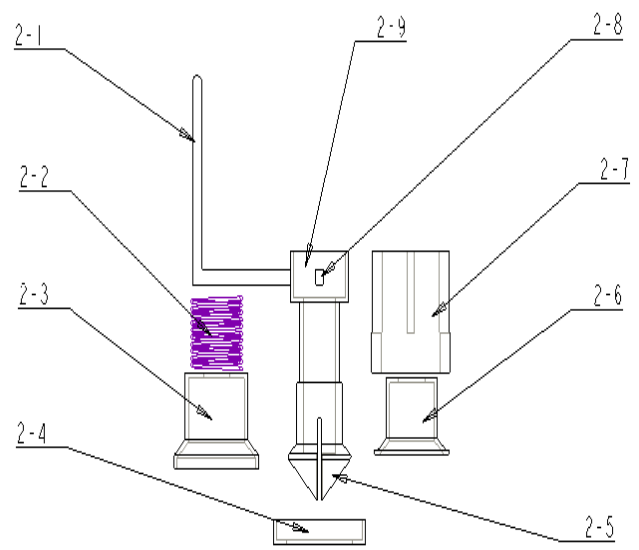

Figure 2. The exploded drawing of the planting device

The max radius of retainer $2-5$ is shorter than the max radius of the stopper 2-4, so it keeps moving down and starts to splays, and the garlic can goes through the retainer 2-5 and trenching device 1 to press a hole on the gully and get buried in this hole. When the cams mechanism 4 reaches its maximum range and retainer 2-5 reaches its lowest point, the reset spring 2-2 will reach its maximum pressure point. At the same time, the oscillating follower 2-1 starts to move up, it get pushed by reset spring 2-2 while the planting pipe 2-9 moves up too, and the retainer 2-5 starts to move up gradually. When the retainer 2-5 moves up, for its splayed size is bigger than 
the minimum radius of tightening ring 2-6 which causes compression that stops the retainer 2-5 continue to shrink.

\section{Interconnection and Function of Cam Mechanism}

Gear 4-2 is connected together by cam shaft transmission gear part 4-4 and spline; the rotation of the gear4-2 drives mechanism's camshaft4-3 starts it rotation. Cam shaft transmission gear part 4-5 and V-shape driving wheel 4-1 are connected together by spline. There is a fixed transfer ratio to define the planting density of garlic. The maximum rotate route can define the depth of the planting garlic and guarantee the quality of the planting garlic.

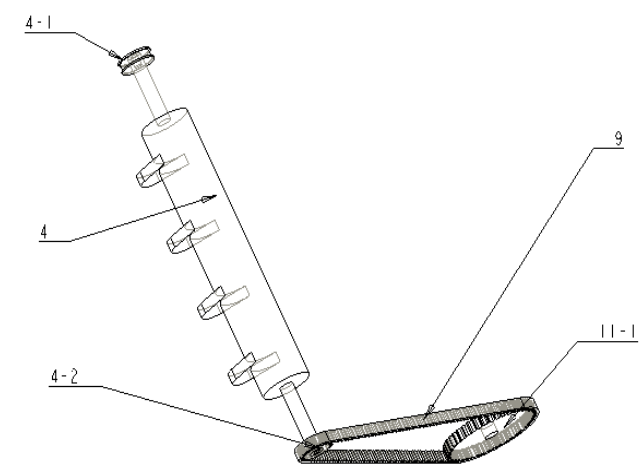

Figure 3. The transmission of the cams mechanism

\section{E. Operation Principle and Working Process}

When the hauling engine is running, it drives the garlic planting machine to move, through connector 5 and drives wheel 11. Wheel 11 drives gear 11-1 to rotate, the gear 111 transmit motion to the gear 4-2 through the cog belt. The Gear 4-2 drive the rotation of the gear 4-2 and it drives mechanism's camshaft 4-3 to starts it rotation and cams mechanism 4 starts to work.Researchers Researchers can define cog belt's transmission ratio by the planting density of garlic. The rotation of the gear4-2 drives mechanism's camshaft4-3 starts it rotation. And the cams mechanism 4 starts to work. The rotation of mechanism's camshaft4-3 drives V-shape driving wheel 4-1 starts its rotation. Vshape driving wheel 4-1 transmits its motion to V-shape driving wheel 7-1 through V-belt8 and drives it to rotate.

$\mathrm{V}$-shape driving wheel is connected with the input shaft of the seed-metering device 7 . It transmits the motion to the input shaft and drives it to rotate. The transmission ratio is defined by the amount of the dropping garlic when seed-metering device 7 rotates one round. The trenching device 1 has some inclination angle and it is half buried in the mud. When the machine is running, the trenching device moves from the mud and makes the gully on the mud through its way. The garlic can goes through the retainer 2-5 and trenching device 1 to press a hole on the gully and get buried in hole. The moving range of slide can be defined by the distance between the planting device and the mud. It can also defined by the depth of the planting garlic in the mud. And the earthing device 3 and press wheel 10 will earth and press the mud.

\section{MAIN COMPONENTS DESIGN}

\section{A. The Design of the Seed-Metering Device}

The rotational speed of Geneva wheel is more stable within the speed range of $9-60 \mathrm{r} / \mathrm{min}$. As what shown in the figure 3, there are eight grooves on the Geneva wheel and the transmission ratio of the V-belt is 8 . The least length of groove is $32.00 \mathrm{~mm}$, the width is $22.00 \mathrm{~mm}$ and the depth is $22.00 \mathrm{~mm}$. This can guarantee the garlic cover will be put into the Geneva wheel in both positions. Now researchers set the rotational speed of Geneva wheel as $15 \mathrm{r} / \mathrm{min}$.

\section{B. The Optionization of Correlation Coefficient}

The structure of the wheel needs to be as simple as possible, it needs to be able to hold the machine and provide the power for the machine through transmission gear wheel. Now researchers chose wheel diameter $d$ as $800 \mathrm{~mm}$ and wheel width B as $180 \mathrm{~mm}$.

\section{Wheel and Cam Mechanism Transmission}

Based on the agriculture requirement, the garlic planting space $\delta$ is $170 \mathrm{~mm}$; the operating speed $\mathrm{V}$ of the puller is $1.2 \mathrm{~m} / \mathrm{s}$. Based on the formula

$$
\mathrm{n} 3=\mathrm{n} 4 \times \mathrm{i} 34
$$

Now bring $\mathrm{n}_{4}=15$ and $\mathrm{i}_{34}=8$ into (1), researchers can get $\mathrm{n}_{3}=120 \mathrm{r} / \mathrm{min}$. The rotational speed of the cams, mechanism is $120 \mathrm{r} / \mathrm{min}$. Based on the formula

$$
\mathrm{V}=\mathrm{n} \times \Pi \times \mathrm{d}
$$

The "V" is the speed $(\mathrm{mm} / \mathrm{min})$ of the puller while the " $\mathrm{d}$ " is the wheel diameter $(\mathrm{mm})$ in the formula. Now researchers know $\mathrm{V}=1.2 \mathrm{~m} / \mathrm{s}, \mathrm{d}=800 \mathrm{~mm}$, bring them into (2), researchers can get $=30 \mathrm{r} / \mathrm{min}$.

The pinion drive gear of cogged belt and pinion drive gear of V-belt are both connected to both sides of the camshaft, so they have the same rotation speed. Therefore, where, $\mathrm{n}_{3}=\mathrm{n}_{2}$. Based on the formula, researchers have

$$
\mathrm{i}_{21}=\frac{\mathrm{n}_{2}}{\mathrm{n}_{1}}
$$

Researchers can get the speed ratio of $\operatorname{cog}$ belt that is equal to 4 .

\section{The Confirmation of Puller's Power}

Now researchers assume the starting torque $\mathrm{T}_{0}$ as the big driving wheel of cog belt, the transmission efficiency is $\eta$, the resistance of the trenching device gets while moving in the mud is F. Based on the formula searched from Mechanical Engineering Handbook:

$$
\mathrm{T}=9550 \mathrm{P} / \mathrm{n}
$$

Where, $\mathrm{P}$ is the driving power, $\mathrm{kW} ; \mathrm{n}$ is the rotational speed, $\mathrm{r} / \mathrm{min}$; $\mathrm{T}$ is the torsion transmitted, Nm. Based on (4), researchers can know that drive gear needs power $\mathrm{P}_{1}=3.14 \mathrm{Kw}$. 


$$
\mathrm{P}=\frac{\mathrm{FV}}{1000}
$$

In the formula, $\mathrm{P}=$ calculated power $\mathrm{KW}, \mathrm{F}=$ tension required $\mathrm{N}$, the linear velocity of the machine $M / S$, researchers get the power of the trenching device needs $\mathrm{P}_{2}=1.2 \mathrm{Kw}$. Therefore, the total power that machine needs is $\mathrm{P}_{\text {Total }}=\mathrm{P}_{1}+4 \times \mathrm{P}_{2}$, and result is $7.94 \mathrm{Kw}$.

Based on the formula $\mathrm{P}=\mathrm{P}_{\text {Need }} / \eta$, researchers take transmission efficiency $\eta$ as 0.8 , and get the power provided by puller is $\mathrm{P}=9.92 \mathrm{kw}$.

\section{E. The Transmission Design of Cog Belt}

Researchers assume the number of the gears of large Gear in the transmission of the gear as $Z_{2}$. The number of the gears of pinion is $Z_{1}$; the rotational speed of large Gear is $n_{2}$, the rotational speed of pinion is $n_{1}$. There the relation can be expressed by:

$$
\frac{\mathrm{Z}_{1}}{\mathrm{Z}_{2}}=\frac{\mathrm{n}_{1}}{\mathrm{n}_{2}}=\mathrm{i}_{12}
$$

The option for the gear material and heat-treatment: researchers choose 45 steel for the pinion, now researchers quenching and tempering it, $\mathrm{HB}=260$, researchers chose 45 steel for large Gear, researchers normalizing it, $\mathrm{HB}=220$.

For the steady loading, the rotational speed of the gear is not high enough, so researchers preliminary select 7 grade precision, in transmission of closed soft tooth surface, the transmission is steady, chose the number of the pinion teeth as $\mathrm{Zl}_{1}=15$ and choose the number of larger Gear teeth as $Z_{2}=60$.

The design calculation of timing belt motion is mainly based on the belt strength, it limits the tension on the unit bandwidth and it maintains belt's service life. The design formula is:

$$
\mathrm{b} \geq \frac{102 \mathrm{P}_{\mathrm{c}}}{\mathrm{Ks} \mathrm{V}\left([\mathrm{F}]-\mathrm{F}_{\mathrm{C}}\right)}
$$

where $\mathrm{b}$ is the bandwidth( $\mathrm{mm}) ; \mathrm{P}_{\mathrm{C}}$ the calculated power( $\mathrm{Kw})$; $\mathrm{K}_{\mathrm{S}}$ mating tooth number engage coefficient; $\mathrm{V}$ the belt speed $(\mathrm{m} / \mathrm{s}) ;[\mathrm{F}]$ the allowable tension on the unit bandwidth $(\mathrm{N} / \mathrm{mm}) ; \mathrm{F}_{\mathrm{C}}$ the centrifugal pull on the unit bandwidth $(\mathrm{N} / \mathrm{mm})$.

And some of the parameters above can be calculated in the following formulas:

$$
\begin{gathered}
\mathrm{P}_{\mathrm{C}}=\left(\mathrm{K}_{\mathrm{A}}+\mathrm{Ks}\right) \mathrm{P} \\
\mathrm{V}=\mathrm{d}_{1} \mathrm{n}_{1} / 19100(\mathrm{~m} / \mathrm{s}) \\
\left\{\begin{array}{r}
\text { If } \quad \mathrm{Z}_{\mathrm{R}}<6, \text { Then } \mathrm{Ks}_{\mathrm{s}}=0.2 \mathrm{Z}_{\mathrm{R}}-0.2 ; \\
\text { If } \quad \mathrm{Z}_{\mathrm{R}} \geq 6, \text { Then } \quad \mathrm{Ks}=1 ;
\end{array}\right. \\
\left\{\begin{aligned}
\text { If } \mathrm{m} \leq 4, \text { Then }[\mathrm{F}]=0.267 \mathrm{~m}^{2}+2933 \mathrm{~m}-1 ; \\
\text { If } \mathrm{m}<4, \text { Then }[\mathrm{F}]=3 \mathrm{~m}+10 ; \\
\mathrm{Fc}=\mathrm{qV}^{2}(\mathrm{~N} / \mathrm{mm})
\end{aligned}\right.
\end{gathered}
$$

Where $\mathrm{q}$ is equal to $12 \times 10^{-4} \mathrm{~m}(\mathrm{~kg} / \mathrm{mm} \cdot \mathrm{m}), \mathrm{K}_{\mathrm{A}}$ application is the factor of the garlic plating machine; Ks the hoard coefficient; $\mathrm{P}$ the transferred power $(\mathrm{Kw})$; $Z_{R}$ the mating tooth number of the pinion, which is nearly equal to $\left[0.5-\left(\mathrm{d}_{2}-\mathrm{d}_{1}\right) / 6 \mathrm{a}\right] \mathrm{Z}_{1}$, while $\mathrm{d}_{1}=\mathrm{mZ}_{1}, \mathrm{~d}_{2}=\mathrm{mz}_{2}$. $Z_{1}$ is the number of big pulley teethes and $Z_{2}$ is the number of the small pulley teethes. $d_{1}, d_{2}$ are the reference diameter of the small cog belt pulley and big cog belt pulley; $\mathrm{m}$ is modulus ( $\mathrm{mm}$ ), the center distance of pulley $(\mathrm{mm}) ; \mathrm{n}_{1}$ the rotational speed of small pulley $(\mathrm{r} / \mathrm{min}) ; \mathrm{q}-$ the mass of unit bandwidth and unit band length $(\mathrm{kg} / \mathrm{mm} \cdot \mathrm{m})$.

The numeric parameters can be found from design handbook, and researchers can easily get: (1) transferred power $\mathrm{P}$, (2) rotational speed of small pulley $\mathrm{n}_{1}$; (3) transmission ratio $\mathrm{i}$; (4) The type and working time of prime move; (5) The type of the working machine; (6) center distance a.

While choosing the belt length as objective function, modulus $\mathrm{m}$ can be determined by the reference, and researchers have chosen the proper bandwidth b.Researchers Researchers can get the bandwidth based on formula

$$
\mathrm{L}=2 \mathrm{a}+\Pi\left(\mathrm{d}_{1}+\mathrm{d}_{2}\right) / 2+\left(\mathrm{d}_{2}-\mathrm{d}_{1}\right)^{2} / 4 \mathrm{a}
$$

\section{1) Choose Transmission Gear Modulus}

Researchers choose modulus $\mathrm{m}=4$, bring $\mathrm{m}$ into formula $d=m z$, researchers can easily get the values of $d_{1}$ and $d_{2}$. The calculation of $[F]$ is the allowable tension on the unit bandwidth.

Now researchers determine the center distance $\mathrm{a}=800 \mathrm{~mm}$, basis on the formula $\mathrm{Z}_{\mathrm{R}} \approx\left[0.5-\left(\mathrm{d}_{2}-\mathrm{d}_{1}\right) / 6 \mathrm{a}\right] \mathrm{Z}_{1}$, researchers can get the value of $Z_{R}$. For $Z_{n}>6$, so researchers choose $\mathrm{Ks}_{\mathrm{s}}=1$. While $\mathrm{m} \leq 4,[\mathrm{~F}]=0.267 \mathrm{~m}^{2}+2.933 \mathrm{~m}-1 ; \mathrm{m}>4,[\mathrm{~F}]=3 \mathrm{~m}+10$; we get $[\mathrm{F}]=15$.

2) Bandwidth Confirmation

Researchers have known rotational speed of small pulley $\mathrm{n}_{1}=120 \mathrm{r} / \mathrm{min}$, now based on formula $\mathrm{Fc}=\mathrm{qV}^{2}$ researchers can get the value $\mathrm{F}_{\mathrm{C}}=1.7 \times 10^{-4}$. Researchers Researchers have known transferred power $\mathrm{p}=1.2 \mathrm{kw}$,

For formula $\mathrm{P}_{\mathrm{C}}=\left(\mathrm{K}_{\mathrm{A}}+\mathrm{K}_{\mathrm{s}}\right) \mathrm{P}$ researchers can get $\mathrm{P}_{\mathrm{C}}$ $=2.4 \mathrm{kw}$. Bring these parameters into formulas, researchers can get $b \geq 43.2$ and $b=60 \mathrm{~mm}$.

3) Vand Length Calculation

According to (13), researchers choose $800 \mathrm{~mm}, 60 \mathrm{~mm}$ and $240 \mathrm{~mm}$ as the value of center distance a, $d_{1}$ and $\mathrm{d}_{2}$ equally. Now take them into (13), researchers can get $\mathrm{L}=2081.4 \mathrm{~mm}$.

\section{CONCLUSIONS}

The main content of this paper is the optimization for integral structure design of the garlic planting machine. Based on the professional knowledge and the existing structure of garlic machine. This garlic planting machine has professional design, it can accord with practical application, it can run in high working efficiency with 
high seeding quality, it can be produced in low cost and it is cost-effective.

\section{ACKNOWLEDGMENT}

The authors gratefully acknowledge the support by Jiangsu Provincial Research Foundation for Basic Research (Jiangsu Provincial Natural Science Foundation) under Grant No. BK20131221.

\section{REFERENCES}

[1] S. Ankri and D. Mirelman, "Antimicrobial properties of allicin from garlic," Microbes and Infection, vol. 2, 1999, pp. 125-129.

[2] M. Corzo-Martı'nez, N. Corzo, and M. Villamiel, "Biological properties of onions and garlic," Trends in Food Science and Technology, vol. 18, 2007, pp. 609-625.

[3] M. Arzanlou and S. Bohlooli, "Introducing of green garlic plant as a new source of allicin," Food Chemistry, vol. 120, no. 1, May 2010, pp.179-183.

[4] T. Guevara-Figueroa, L. López-Hernández, M.G. Lopez, et al, "Conditioning garlic "seed" cloves at low temperature modifies plant growth, sugar, fructan content, and sucrose sucrose fructosyl transferase (1-SST)", Scientia Horticulturae, vol. 189, June 2015, pp. 150-158.

[5] Z. Y. Jiang and J. M. Tang, "Optimal design of intermittent conveyor of geneva mechanism," Light Industry Machinery, no. 5, 2008, pp.40-42

[6] F. Wang, "Design and analysis of garlic seeder's major part," Journal of Agricultural Mechanization Research, no. 8, 2010, pp.90-93.

[7] Y. Y. Shao, Q. L. Zeng, and G. T. Xuan, et al., "Kinematics simulation and optimization for transplanting mechanism of garlic planting machine," Journal of Agricultural Mechanization Research, no. 1, 2013, pp.64-67.

[8] J. Wang Juan, L. Shi, and C. Yuan, et al., "Garlic clove recognition and steering design," Journal of Agricultural Mechanization Research, no. 6, 2013, pp.94-97.

[9] R. Li, X. Sun, and C. Song, et al., "Summary and research of model WZ-4 garlic transplanting machine," Agricultural Equipment \& Vehicle Engineering. no. 5, 2013, pp.15-17.

[10] R. Cui, H. Zhang, and W. Xu, et al., "Discussion on the present situation and development of garlic mechanized production in China," Journal of Agricultural Mechanization Research, no. 3 , 2015, pp.264-268. 